\title{
Formulation and evaluation of fast dissolving tablets of amlodipine besylate by using Fenugreek seed mucilage and Ocimum basilicum gum
}

\author{
*Sudheshnababu Sukhavasi, V. Sai kishore \\ Department of Pharmaceutics, Bapatla College of Pharmacy, Bapatla-522101, Andhra Pradesh, India
}

\begin{abstract}
Fast dissolving/disintegrating tablets have received ever-increasing demand during the last decade, and the field has became a rapidly growing area in the pharmaceutical area. Particularly the fast dissolving drug delivery systems formulated with natural polymers have more demand because natural materials like gums and mucilages have been extensively used in the field of drug delivery for their easy availability, ease administration, non toxicity, non irritant nature etc. The main aim of the present study was to formulate the fast dissolving tablets of amlodipine besylate tablets using Fenugreek seed mucilage and Ocimum basilicum gum as a natural superdisintegrating agents to achieve quick onset of action, is to increase the water uptake with in shortest wetting time and there by decrease the disintegration time of the tablets by simple and cost effective direct compression technique. Pre-compression parameters like angle of repose and post-compression parameters like wetting time, water absorption ratio, in-vitro disintegration and in-vitro dispersion time were studied. The hardness, friability and drug content of all the formulations were found to be within the limits. The best formulations FFGK5 \& FOB5 have shown good disintegration time, hardness and friability. The best formulations were also found to be stable. Optimized formulation was subjected to stability studies as per ICH guidelines and it insignificant change in hardness, disintegration time and in vitro drug release.
\end{abstract}

Key Words: Amlodipine besylate, Natural superdisintegrants, Extraction, Direct compression, Disintegration time.

\section{INTRODUCTION}

The most popular solid dosage forms are being tablets but one important drawback of these dosage form for some patients, is the difficulty to swallow (Ito and Sugihara, 1996). For these reasons tablets that can fast dissolve or disintegrate in the oral cavity have attracted a great deal of attention. Fast disintegrating tablets are not only indicated for people who have swallowing difficulties, but also are ideal for active people. Fast dissolving tablets are also called as mouth-dissolving tablets, melt-in mouth tablets, Orodispersible tablets, rapimelts, porous tablets, quick dissolving etc. (Seager, 1998; Chang et al., 2000). The advantages of fast dissolving dosage forms are increasingly being recognized in both industry and academia. The fast disintegrat-

\footnotetext{
*Corresponding Author:

Sudheshnababu Sukhavasi

Department of Pharmaceutics

Bapatla College of Pharmacy

Bapatla-522101, Andhra Pradesh, India.

E-mail: sudheshnababu@yahoo.com

Contact No.: 9885953637
}

ing tablets prepared by direct compression method, in general, are based on the action established by natural and synthetic superdisintegrants (Jain et al., 2012).

Amlodipine (as besylate, mesylate or maleate) is a long-acting calcium channel blocker (dihydropyridine (DHP) class) used as an anti-hypertensive and in the treatment of angina. Like other calcium channel blockers, amlodipine acts by relaxing the smooth muscle in the arterial wall, decreasing total peripheral resistance and hence reducing blood pressure; in angina it increases blood flow to the heart muscle (Bhardwaj et al., 2010).

Majority of investigations on natural polymers in drug delivery systems are centered on polysaccharides and proteins (Tripathy et al., 2004). Number of natural, synthetic and semi synthetic polymer materials is used in the various drug delivery systems (Bharadia et al., 2004). Many substances are used as natural, synthetic and semi synthetic polymers but mucilage of natural origin is more 
Table 1: Composition of Amlodipine Besylate Fast Dissolving Tablets.

\begin{tabular}{clllllllllll}
\hline S1. No. Ingredients (mg) & \multicolumn{2}{l}{ FFGK1 } & FFGK2 & FFGK3 & FFGK4 & FFGK5 & FOB1 & FOB2 & FOB3 & FOB4 & FOB5 \\
\hline 1 & Amlodipine besylate & 10 & 10 & 10 & 10 & 10 & 10 & 10 & 10 & 10 & 10 \\
2 & Fenugreek seed mucilage & 2 & 4 & 6 & 8 & 10 & - & - & - & - & - \\
3 & Ocimum basilicum gum & - & - & - & - & - & 2 & 4 & 6 & 8 & 10 \\
4 & MCC & 100 & 100 & 100 & 100 & 100 & 100 & 100 & 100 & 100 & 100 \\
5 & Magnesium stearate & 1.5 & 1.5 & 1.5 & 1.5 & 1.5 & 1.5 & 1.5 & 1.5 & 1.5 & 1.5 \\
6 & Talc & 2 & 2 & 2 & 2 & 2 & 2 & 2 & 2 & 2 & 2 \\
7 & Mannitol & 84.5 & 82.5 & 80.5 & 78.5 & 76.5 & 84.5 & 82.5 & 80.5 & 78.5 & 76.5 \\
\hline
\end{tabular}

preferred over synthetic and semi synthetic substances because they are comparatively cheap, abundantly available, non-toxic and non-irritating in nature (Poddar et al., 2004).

In this study, natural substances like Fenugreek seed mucilage and Ocimum basilicum gum were used as superdisintegrants in the formulation of amlodipine besylate fast dissolving tablets by direct compression method.

\section{MATERIALS AND METHODS}

Amlodipine besylate was received as a gift sample from Orchid Pharmaceuticals. Fenugreek seeds and Ocimum basilicum seeds was obtained from local market. Mannitol, Magnesium stearate, Talc was obtained from S.D. FINE chemicals, Mumbai.

\section{Extraction of mucilage from fenugreek seeds}

The seeds are powdered using pestle and mortar and $100 \mathrm{~g}$ of the powder is extracted with hexane to remove lipophilic compounds using a soxhelet apparatus. To remove pigments and to deactivate enzyme, the defatted powder is boiled in ethanol for $20 \mathrm{~min}$. This treated powder is then soaked in 10 liters water and the $\mathrm{pH}$ is adjusted to 3.5 using $0.5 \mathrm{M}$ Hydrochloric acid. The mixture is stirred by a mechanical stirrer for $12 \mathrm{~h}$ and then filtered through filtration paper. The filtrate is centrifuged (5000 RPM) and the supernatant is concentrated in vacuum to $50 \%$ of its initial volume. The resulting solution is mixed with the same volume of $96 \%$ ethanol and stored in a refrigerator for $4 \mathrm{~h}$. The precipitated mucilage is separated by centrifugation (5000 RPM). The collected mucilage is re-suspended in distilled water, agitated for $20 \mathrm{~min}$ and reprecipitated one more time to eliminate chloride ions and other impurities. Finally the residue is washed with diethyl ether and acetone and dried overnight at $45^{\circ} \mathrm{C}$, resulting in an off-white powder (Kumar et al., 2009).

\section{Extraction of Ocimum basilicum gum}

The seeds were rinsed with given volume of water in a short time and mixed with water (in a given ratio of water/seed) at a specific $\mathrm{pH}$ and temperature and enough time was given to reach the stage where the seeds were completely swelled (20 min agitation, $1000 \mathrm{rpm})$. Gum separation from the swelled seeds was done by passing the seeds through an extractor (Pars Khazar 700P, Rasht, Iran) with a rotating rough plate that scraped the gum layer on the seed surface. The separated gum was collected and the residual gums adhered to the seeds was subjected to immersion in water and the rotating extractor. This procedure was done four times. The collected gum from the different stages was mixed, filtered (by a cheese cloth) and dried by vacuum oven at $50^{\circ} \mathrm{C}$. Finally, the dried extracted gums were then ground and packed in the plastic bags and stored under dry and cool conditions (Razavi et al., 2009).

\section{Standard calibration curve}

Solutions ranging from 2 to $10 \mu \mathrm{g} / \mathrm{ml}$ were prepared in phosphate buffer ( $\mathrm{pH} 6.8$ fluid). Absorbance was measured for each solution at $\lambda_{\max }$ of $361 \mathrm{~nm}$, using Shimadzu UV spectrophotometer.

Drug-excipient compatibility study by IR spectroscopy The physico-chemical compatibility between Amlodipine besylate and the excipients used in the research was tested by IR spectroscopy using Perkin Fourier Transform Infrared Spectrophotometer. The samples were scanned under diffuse reflectance mold and graph was plotted by $\mathrm{KBr}$ pellet technique. The spectra were recorded in the wave number region between $4400 \mathrm{~cm}^{-1}$ to $400 \mathrm{~cm}^{-1}$. The individual spectra 
Table 2: Evaluation parameters of amlodipine besylate fast dissolving tablets.

\begin{tabular}{|c|c|c|c|c|c|c|c|c|c|c|}
\hline Parameters & FFGK1 & FFGK2 & FFGK3 & FFGK4 & FFGK5 & FOB1 & FOB2 & FOB3 & FOB4 & FOB5 \\
\hline $\begin{array}{l}\text { Angle of Repose } \\
(\theta)\end{array}$ & $28^{\circ} 42^{\prime}$ & $24^{\circ} 65^{\prime}$ & $27^{\circ} 44^{\prime}$ & $26^{\circ} 41^{\prime}$ & $24^{\circ} 52^{\prime}$ & $30^{\circ} 60^{\prime}$ & $28^{\circ} 60^{\prime}$ & $27^{\circ} 10^{\prime}$ & $26^{\circ} 30^{\prime}$ & $24^{\circ} 30^{\prime}$ \\
\hline Carr's index \% & $15.92 \pm 0.65$ & $15.87 \pm 0.65$ & $14.59 \pm 0.66$ & $15.54 \pm 0.58$ & $15.91 \pm 0.55$ & $15.54 \pm 0.24$ & $15.08 \pm 0.65$ & $14.25 \pm 0.89$ & $13.64 \pm 0.94$ & $13.46 \pm 0.82$ \\
\hline Thickness (mm) & $2.92 \pm 0.55$ & $2.73 \pm 0.24$ & $2.83 \pm 0.32$ & $2.9 \pm 0.33$ & $2.96 \pm 0.85$ & $2.83 \pm 0.55$ & $2.94 \pm 0.24$ & $2.98 \pm 0.63$ & $3.1 \pm 0.66$ & $3.3 \pm 0.98$ \\
\hline $\begin{array}{l}\text { Hardness } \\
\left(\mathrm{kg} / \mathrm{cm}^{2}\right)\end{array}$ & $2.9 \pm 0.22$ & $2.8 \pm 0.55$ & $2.8 \pm 0.51$ & $3.1 \pm 0.69$ & $2.8 \pm 0.25$ & $2.7 \pm 0.32$ & $3.2 \pm 0.33$ & $3.3 \pm 0.65$ & $3.28 \pm 0.69$ & $3.3 \pm 0.58$ \\
\hline Drug content(\%) & $99.61 \pm 0.45$ & $101.31 \pm 0.25$ & $99.54 \pm 0.55$ & $99.79 \pm 0.58$ & $99.82 \pm 0.54$ & $99.44 \pm 0.06$ & $99.31 \pm 0.41$ & $99.48 \pm 0.52$ & $100.11 \pm 0.44$ & $99.82 \pm 0.21$ \\
\hline $\begin{array}{l}\text { Weight } \\
\text { variation (mg) }\end{array}$ & $199 \pm 0.65$ & $200 \pm 0.55$ & $201 \pm 0.58$ & $199 \pm 0.69$ & $199 \pm 0.28$ & $199 \pm 0.65$ & $201 \pm 0.69$ & $199 \pm 0.44$ & $199 \pm 0.32$ & $201 \pm 0.54$ \\
\hline Friability(\%) & $0.29 \pm 0.12$ & $0.42 \pm 0.25$ & $0.51 \pm 0.58$ & $0.58 \pm 0.36$ & $0.52 \pm 0.64$ & $0.69+0.02$ & $0.72+0.03$ & $0.77+0.09$ & $0.79+0.12$ & $0.83+0.09$ \\
\hline $\begin{array}{l}\text { Wetting time } \\
\text { (sec) }\end{array}$ & 45 & 33 & 29 & 22 & 18 & 55 & 42 & 36 & 28 & 21 \\
\hline $\begin{array}{l}\text { Water absorption } \\
\text { ratio }(\%)\end{array}$ & 35 & 47 & 58 & 69 & 84 & 33 & 49 & 54 & 74 & 83 \\
\hline $\begin{array}{l}\text { Dispersion time } \\
\text { (min) }\end{array}$ & 3 & 2.6 & 2.1 & 1.9 & 1 & 3.9 & 3.2 & 2.9 & 2.3 & 2 \\
\hline $\begin{array}{l}\text { disintegration } \\
\text { time }(\mathrm{sec})\end{array}$ & 120 & 110 & 75 & 55 & 38 & 95 & 84 & 76 & 58 & 32 \\
\hline
\end{tabular}

obtained for Amlodipine besylate, excipients were compared with the spectra of the physical mixture of Amlodipine besylate and excipients.

\section{Preparation of Fast Dissolving Tablets of Amlodi- pine Besylate}

Fast dissolving tablets of amlodipine besylate was prepared by direct compression method. The drug and excipients were passed through sieve no. 80 to ensure better mixing, natural superdisintegrants Fenugreek seed mucilage and Ocimum basilicum gum were used in different proportions. The powders were compressed into tablets on tablet punching machine (Cadmach, India) using $9 \mathrm{~mm}$ punch and weight of the tablet is $200 \mathrm{mg}$ [Table 1].

\section{EVALUATION}

\section{Precompression Parameters}

Angle of Repose $(\theta)$ : The friction forces in a loose powder can be measured by the angle of repose $(\theta)$. It is an indicative of the flow properties of the powder. It is defined as maximum angle possible between the surface of the pile of powder and the horizontal plane.

$\operatorname{Tan}(\theta)=\mathrm{h} / \mathrm{r}$

$\theta=\tan -1(\mathrm{~h} / \mathrm{r})$

Where, $\theta$ is the angle of repose. $\mathrm{h}$ is the height in $\mathrm{cms}$

$\mathrm{r}$ is the radius in $\mathrm{cms}$.

Bulk Density $(\mathrm{Db})$ : It was the ratio of total mass of powder to the bulk volume of powder. It was measured by pouring the weight powder (passed through standard sieve \# 20) into a measuring cylinder and initial weight was noted. This initial volume was called the bulk volume. From this the bulk density was calculated according to the formula mentioned below. It was expressed in $\mathrm{g} / \mathrm{ml}$ and is given by:

$\mathrm{Db}=\mathrm{M} / \mathrm{Vb}$

Where, $\mathrm{M}$ is the mass of powder

$\mathrm{Vb}$ is the bulk volume of the powder.

Tapped Density $\left(D_{t}\right)$ : It was the ratio of total mass of the powder to the tapped volume of the powder. Volume was measured by tapping the powder for 750 times and the tapped volume was noted, if the difference between these two volumes was less than $2 \%$. If it was more than $2 \%$, tapping was continued for 1250 times and tapped volume was noted. Tapping was continued until the difference between successive volumes was less than $2 \%$ (in a bulk density apparatus). It was expressed in $\mathrm{g} / \mathrm{ml}$ and was given by:

$\mathrm{Dt}=\mathrm{M} / \mathrm{Vt}$ 
Where, $\mathrm{M}$ is the mass of powder

$\mathrm{Vt}$ is the tapped volume of the powder.

\section{Powder flow properties}

The flow properties were determined by

Carr's index (or) \% compressibility: It indicates powder flow properties. It is expressed in percentage and is given by:

$\mathrm{I}=\mathrm{Dt}-\mathrm{Db} / \mathrm{Dt} \times 100$

Where, Dt is the tapped density of the powder and

$\mathrm{Db}$ is the bulk density of the powder.

Hausner ratio: Hausner ratio is an indirect index of ease of powder flow. It is calculated by the following formula:

Hausner ratio $=\mathrm{Dt} / \mathrm{Db}$

Where, Dt is the tapped density.

$\mathrm{Db}$ is the bulk density.

Lower hausner ratio $(<1.25)$ indicates better flow properties than higher ones $(>1.25)$.

\section{Postcompression parameters}

\section{Thickness}

Thickness was measured by using varnier calipers.

\section{Hardness}

The hardness of tablet was measured by Monsanto hardness tester. The hardness was measured in terms of $\mathrm{kg} / \mathrm{cm}^{2}$.

\section{Drug content}

Twenty tablets were powdered, and $10 \mathrm{mg}$ equivalent weight of Amlodipine besylate in tablet powder was accurately weighed and transferred into a $100 \mathrm{ml}$ volumetric flask. Initially, $5 \mathrm{ml}$ methanol was added and shaken for $10 \mathrm{~min}$. Then, the volume was made up to $100 \mathrm{ml}$ with 6.8 phosphate buffer. The solution in the volumetric flask was filtered, diluted suitably and analyzed spectrophotometrically at $361 \mathrm{~nm}$.

\section{Uniformity of weight}

Twenty tablets were randomly selected from each formulation, individually weighed, the average weight and standard deviation was calculated.

\section{Friability}

Roche friabilator was used to determine the friability. Pre weighed tablets were placed in friabilator and rotated at a speed of $25 \mathrm{rpm}$ for 4 minutes or up to 100 revolutions. The tablets are dropped from a

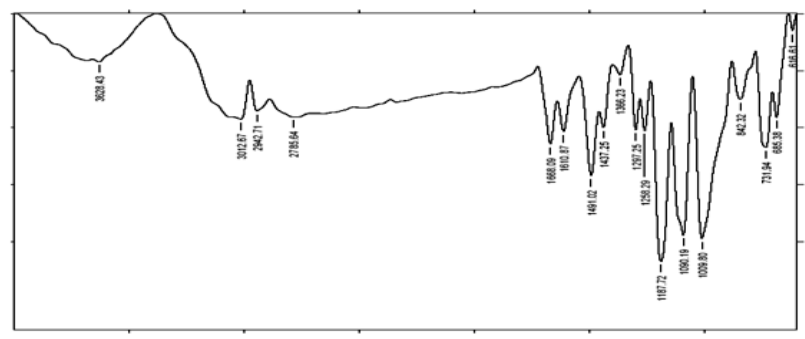

Figure 1: IR Spectrum of Amlodipine besylate.

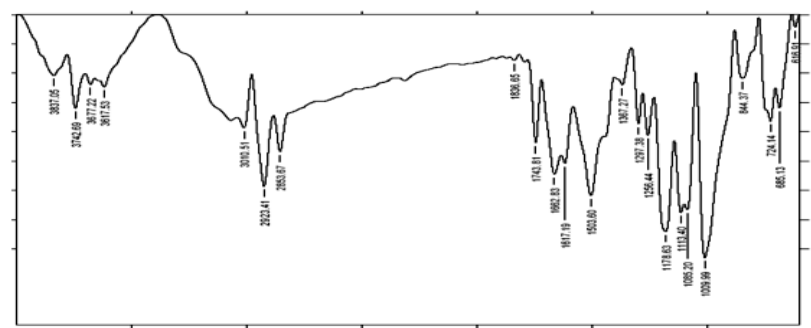

Figure 2: IR Spectrum of Amlodipine besylate + FGK.

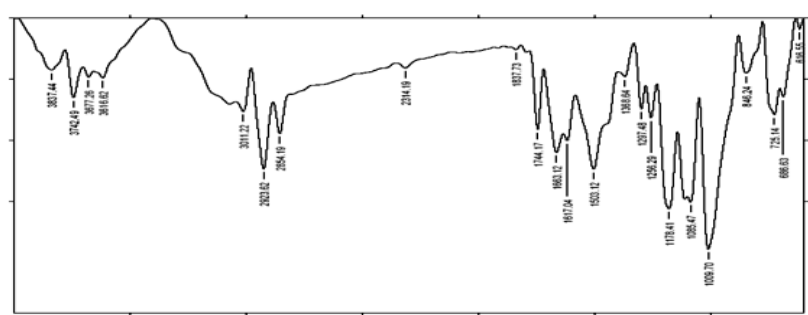

Figure 3: IR Spectrum of Amlodipine besylate + OB.

distance of 6 inches in each revolution. The tablets were then reweighed after removal of fines and the percentage of weight loss was calculated.

$\%$ Friability $=\frac{\text { Initial Weight }- \text { Final Weight }}{\text { Initial Weight }} \times 100$

\section{Wetting time and Water absorption ratio}

A piece of paper folded twice was kept in a Petri dish containing $6 \mathrm{ml}$ of purified water. A tablet having a small amount of Rosaline dye powder on the upper surface was placed on the tissue paper. The time required to develop a red colour on the upper surface of the tablet was recorded as the wetting time. Test was done with the same procedure as that of wetting time. In this test initial weight of tablet was taken before placing on petri dish. After complete wetting the wetted tablet was then weighed. Water absorption ratio, $\mathrm{R}$ was determined using the equation: 
$R=\left[W b-\frac{W a}{W b}\right] \times 100$

Where, $\mathrm{Wa}$ and $\mathrm{Wb}$ were the weights of the tablet before and after water absorption.

\section{In vitro dispersion time}

Tablet was added to $10 \mathrm{ml}$ of phosphate buffer solution $\mathrm{pH} 6.8\left(\mathrm{pH}\right.$ of saliva) at $37 \pm 0.5^{\circ} \mathrm{C}$. Time required for complete dispersion of tablet was measured.

\section{In vitro disintegration test}

The disintegration time was measured using disintegration test apparatus. One tablet was placed in each tube of the basket. The basket with the bottom surface made of a stainless-steel screen (mesh no.10) was immersed in water bah a $37 \pm 2^{\circ} \mathrm{C}$. The time required for complete disintegration of the tablet in each tube was determined using a stop watch. To be complied with the pharmacological standards, dispersible tablets must disintegrate within 3 min when examined by the disintegration test for tablets.

\section{In-vitro Dissolution Study}

The release rate Amlodipine Besylate from fast dissolving tablets is determined using United State Pharmacopoeia (USP) XXIV dissolution testing apparatus II (paddle method). The dissolution test was performed using $900 \mathrm{ml}$ of $\mathrm{pH} 6.8$ buffer, at $37 \pm 0.5^{\circ} \mathrm{C}$ and $50 \mathrm{rpm}$. A sample $(5 \mathrm{ml})$ of the solution is withdrawn from the dissolution apparatus at regular intervals for $10 \mathrm{~min}$. The samples are replaced with fresh dissolution medium of same quantity. The samples are filtered through a $0.45 \mu$ membrane filter. Absorbance of these solutions is measured at $361 \mathrm{~nm}$ using a Shimadzu UV/Vis double beam spectrophotometer. Cumulative percentage of drug release is calculated using an Equation obtained from a standard curve. (Chowdary and Hemavathy, 2000; Rizk, 1997; Mishra et al., 2005).

\section{Stability Studies}

The stability study of the tablets was carried out according to ICH guidelines by storing tablets in stability chamber at $25 \pm 20^{\circ} \mathrm{C} / 60 \pm 5 \% \mathrm{RH}$ and $40 \pm 20^{\circ} \mathrm{C} / 75 \pm 5 \% \mathrm{RH}$ for 3 months. The effects of temperature and time on the physical characteristics of the tablet are evaluated for assessing the stability of the prepared formulations. The different parame-

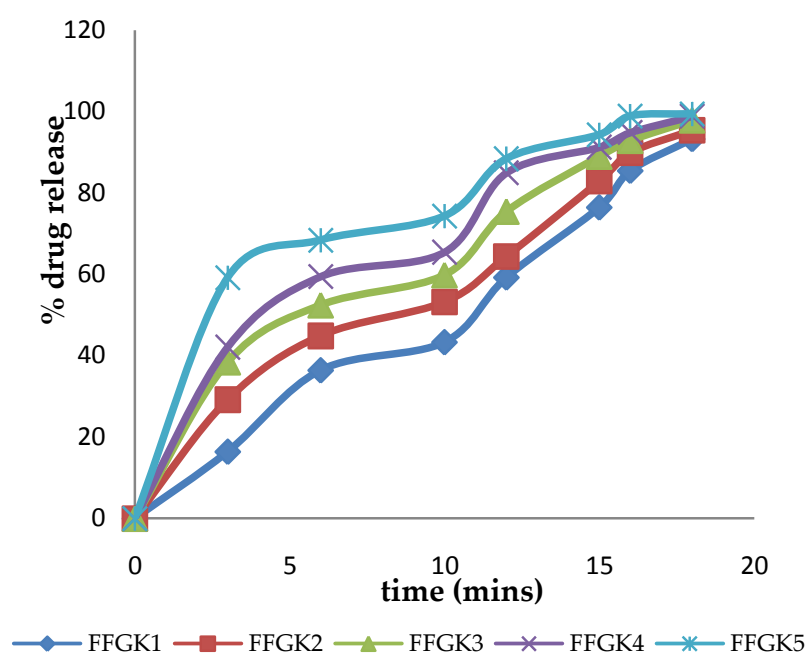

Figure 4: Dissolution profile of FGK Formulation.

ters that are to be studied are disintegration time, hardness, friability, drug content and dissolution rate (Natalie, 1997).

\section{RESULTS AND DISCUSSION}

Fast dissolving tablets acts as a major role to eradicate different types of circumstantial attacks of various diseases in the market. Many patients, especially elderly find it difficult in swallowing tablets, capsules, fluids and thus do not comply with prescription, which results in high incidence of non compliance oriented research has resulted in bringing out many safer and newer drug delivery systems.

Rapidly disintegrating/dissolving tablet is one of such example, for the reason of rapid disintegration or even with saliva. Significance of this drug delivery system includes ease administration, improved patient compliance, rapid onset of action and may offer an improved bioavailability, ideal for pediatric and geriatric patients and rapid onset of action.

Fast dissolving tablets of amlodipine besylate were prepared by adding natural superdisintegrating agents i.e. Fenugreek seed mucilage and Ocimum basilicum gum.

IR spectra of Amlodipine besylate and its physical mixture with formulation excipients were determined using FT-IR. And found, there is no 


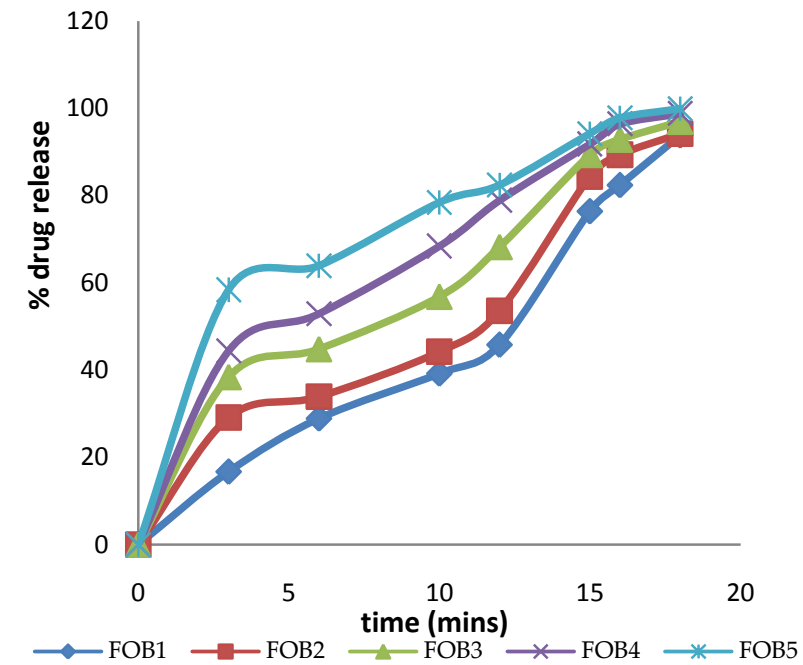

Figure 5: Dissolution profile of OB Formulation.

interaction between the drug and excipients [Figure $1,2,3]$. The pre-compression parameters of all the formulations were depicted in the Table 2. The angle of repose, bulk density, tapped density, Carr's index and hausner's ratio shows good flowability in almost all the formulations resulting suitable for the preparation of Fast dissolving tablets.

The prepared tablets were evaluated for different parameters and results were depicted in Table $\mathbf{1}$. Thickness of the formulations FFGK1 to FFGK5 varied from $2.73 \pm 0.24$ to $2.96 \pm 0.85 \mathrm{~mm}$ while of formulations FOB1 to FOB5 showed from $2.83 \pm 0.55$ to $3.3 \pm 0.98 \mathrm{~mm}$ respectively. The hardness was uniformly maintained and it was found to be within $2.7 \pm 0.32$ to $3.3 \pm 0.65 \mathrm{~kg} / \mathrm{cm}^{2}$. Percent friability was less than $1 \%$ in the entire formulations and the values obtained lies within $0.29 \pm 0.12$ to $0.83 \pm 0.09$ and found within the range only. The percentage weight variation for all the formulations are tabulated in Table 2. All the tablets passed weight variation test as the $\%$ weight variation was within the pharmacopoeial limits of $\pm 7.5 \%$. The percentage drug content of all the tablets was found to be between $99.11 \pm 0.54$ to $101.31 \pm 0.25$, which was within the acceptable limits.

Tablets from each batch show immediate disintegration. Disintegration time decreases with increase in concentration of the disintegrants. Disintegration time was given in Table 2. The rapid disintegration

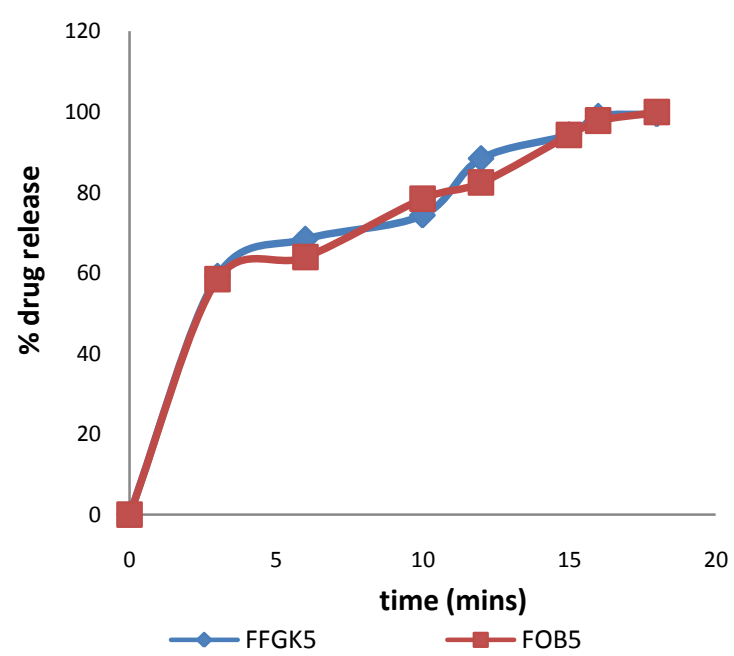

Figure 6: Dissolution profile of optimized formulations.

was seen in the formulation FFGK5 containing Fenugreek seed mucilage as superdisintegrating agent. This is due to the rapid uptake of water from the medium, swelling and burst effect. As in the Ocimum basilicum gum FOB5 also same. As the concentration increases the disintegration time decreases profoundly.

The wetting time was rapid in all the formulations. wetting is closely related to inner structure of tablets. This may be due to ability of swelling and also capacity of absorption of water. The results were depicted in the Table 2. The water absorption ratio that is the uptaking of water was very fast and the ratio was found higher.

Dissolution profile of the formulations FFGK1, FFGK2, FFGK3, FFGK4, FFGK5 and formulations FOB1, FOB 2, FOB 3, FOB 4, and FOB 5 is shown in Figure 4,5 . As the concentration of the polymer increased there was decrease in the disintegration time and increase in dissolution of drug. $90 \%$ of the drug was released from the all the formulations within 15 minutes.

From drug release it was observed that increase in concentration of superdisintegrant increases the drug release. Therefore formulation FFGK5 and FOB5 was selected as the optimized formulation as it showed good release, good wetting property, and good precompression and good post compression results. 
From the values obtained, it is proved that all the formulations FFGK1 to FFGK5 and FOB1 to FOB5 dissolution (release) of the drugs follows first order.

The optimized formulations FFGK5 and FOB5 were kept for accelerated stability and monitored for appearance, hardness, friability, drug content, in vitro dispersion time, wetting time and dissolution profile study and found to stable for all the different parameters [Figure 6].

\section{CONCLUSION}

In the present study the superdisintegrant property of Fenugreek seed mucilage and Ocimum basilicum gum has been explored. Extensive swelling, porosity and wicking action of the natural material in the fast dissolving tablet formulation were found to be contributing its superdisintegrant action. The tablets disintegrated much faster and consistently when Fenugreek seed mucilage and Ocimum basilicum gum was used as superdisintegrant compared to synthetic superdisintegrants. Fenugreek seed mucilage and Ocimum basilicum gum could be used for different applications in tablet dosage forms and may be explored as high functionality excipients for future applications.

\section{REFERENCES}

Bharadia, P.D., Patel, M.M., Patel, G.C., Patel, G.N. (2004). A preliminary investigation on sesbania gum as a pharmaceutical excipients. Int J Pharma Excip, 3, 99-102.

Bhardwaj, V., Shukla, V., Goyal, N., Salim, M.D., Sharma P.K. (2010). Formulation and evaluation of fast disintegrating sublingual tablets of amlodipine besylate using different superdisintegrants. International Journal of Pharmacy and Pharmaceutical Sciences, 2( 3):82-89. [DOI]

Chang, R.K., Guo, X., Burnside, B., Couch, R. (2000). Fast dissolving tablets. Pharm Technol, 24, 52-8.

Chowdary, K.P., Hemavathy, R. (2000). Formulation and dissolution rate studies on dispersible tablets of ibuprofen. Indian J Pharm Sci, 63, 213-16.

Ito, A., Sugihara, M. (1996). Development of Oral Dosage Forms for Elderly Patients: Use of Ager as Base of Rapidly Disintegrating Oral Tablets. Chemical \& Pharmaceutical Bulletin, 11(44), 2132-36. [DOI]

Jain, N., Mandal, S., Banweer, J., Jain, S. (2012). Effect of superdisintegrants on formulation of taste masked fast disintegrating Ciprofloxacin tablets. International Current Pharmaceutical Journal, 1(4), 62-67. [DOI]
Kumar, R., Patil, S., Patil, M.B., Patil, S.R., Paschapur, M.S. (2009). Isolation and Evaluation of Disintegrant Properties of Fenugreek Seed Mucilage. International Journal of PharmTech Research, 1(4), 982-996.

Mishra, D.N., Bindal, M., Singh, S.K., Kumar, S.G.V. (2005). Rapidly disintegrating oral tablets of Meloxicam. Indian Drugs, 42 Suppl 10, 685-87.

Natalie, M.C. (1997). Stability studies in overview of ICH Guidelines for Drug Products. Matrix Pharmaceutical Inc.

Poddar, S.S., Saini, C.R., Paresh, A., Singh, R. (2004). The microencapsulation of ibuprofen by gelatincarrageenan complex coacervation. Scientific abstract, 56th Indian Pharmaceutical Congress, pp: AP111.

Razavi, S.M.A., Mortazavi, S.A., Matia-Merino, L., HosseiniParvar, S.H., Motamedzadegan, A., Khanipour, E. (2009). Optimisation study of gum extraction from Basil seeds (Ocimum basilicum L.). International Journal of Food Science and Technology, 44:1755-1762.

Rizk, S. (1997). Investigation on a new modified USP Xanthan with tablet disintegration properties. Drug Dev Ind Pharm, 23, 19-26. [DOI]

Seager, H. (1998). Drug delivery products and the zydis fast dissolving dosage forms. J Pharm Pharmacol, 50 Suppl 4, 375-82. [DOI]

Tripathy, S., Promod, K., Banthia A.K. (2004). Novel delivery system for aceclofenac. Scientific abstract, 56th Indian Pharmaceutical Congress, pp: A71. 